\title{
Effect of acidic primers on adhesive bonding of tri- $n$-butylborane initiated adhesive resin to alumina
}

\author{
Hiroyasu Koizumi ${ }^{1,2)}$, Daisuke Nakayama ${ }^{3)}$, Yusuke $\mathrm{Oba}^{3)}$, Kazuya Yamada ${ }^{1)}$ \\ and Hideo Matsumura ${ }^{1,2}$ \\ ${ }^{1)}$ Department of Fixed Prosthodontics, Nihon University School of Dentistry, Tokyo, Japan \\ ${ }^{2)}$ Division of Advanced Dental Treatment, Dental Research Center, Nihon University School of Dentistry, \\ Tokyo, Japan \\ ${ }^{3)}$ Division of Applied Oral Sciences, Nihon University Graduate School of Dentistry, Tokyo, Japan
}

(Received 19 August and accepted 27 September 2010)

\begin{abstract}
The present study was conducted to evaluate the effect of acidic primers on adhesive bonding to sintered alumina. Alumina disk specimens were primed with one of the following acidic materials: Acryl Bond, All Bond II Primer B, Alloy Primer, Estenia Opaque Primer, Eye Sight Opaque Primer, M.L. Primer, MR. Bond, and Super-Bond Liquid. The disks were bonded with an adhesive resin (Super-Bond) initiated with a tri- $n$-butylborane (TBB) derivative, and bond strengths were determined. Average bond strength before thermocycling varied from 42.9 to 44.3 $\mathrm{MPa}$, whereas post-thermocycling bond strength ranged from 22.0 to $42.8 \mathrm{MPa}$. Of the nine groups assessed, reduction of bond strength after thermocycling was not significant in three: Alloy Primer, Estenia Opaque Primer, and Eye Sight Opaque Primer. It can be concluded that phosphate-based primers are recommended for bonding sintered alumina with SuperBond resin. (J Oral Sci 52, 571-576, 2010)
\end{abstract}

Keywords: alumina; acidic primer; bonding; tri- $n$-butylborane.

Correspondence to Dr. Hiroyasu Koizumi, Department of Fixed Prosthodontics, Nihon University School of Dentistry, 1-8-13 Kanda-Surugadai, Chiyoda-ku, Tokyo 101-8310, Japan

Tel: +81-3-3219-8145

Fax: +81-3-3219-8351

E-mail: Koizumi@dent.nihon-u.ac.jp

\section{Introduction}

Application of adhesive systems for seating ceramic restorations and fixed partial dentures (FPDs) has increased substantially. Aluminum oxide (alumina) has been used as a reinforcing component of dental feldspathic materials (1), and highly purified alumina has been introduced as a prefabricated coping material for a ceramic restorative system (2). It is of benefit to both patients and clinicians that alumina or alumina-based coping materials and abutment teeth can be bonded durably for an extended period for servicing of restorations and FPDs. Numerous papers have reported the effectiveness of adhesive systems for bonding alumina (3-16) and alumina-based materials (17-19). In a pioneering study of adhesive bonding of alumina and quartz, it was found that a carboxylic monomer was effective for bonding between alumina and an acrylic resin (3). Silane agents and/or surface preparations with silicon compounds have also been introduced for bonding alumina ceramic materials $(3-6,8-11,13,14)$. Unlike silicabased materials, application of acidic compounds enhances bonding to alumina (3,6-16).

Although a number of adhesive systems for bonding ceramic restorations and FPDs are being introduced, only limited information is available about the bonding behavior of high-purity alumina, especially in relation to functional monomers in the bonding agents $(3,15)$. The purpose of the present study was to evaluate the effect of acidic primers on bond strength of an acrylic resin joined to high-purity alumina. 


\section{Materials and Methods}

High-purity $(99.7 \%)$ alumina sintered at $1,600^{\circ} \mathrm{C}$ for 5 days (Furuuchi Chemical Corp., Tokyo, Japan) was employed. Disk specimens of two sizes (10 and $8 \mathrm{~mm}$ in diameter by $3 \mathrm{~mm}$ thick) were prepared as the bonding substrates. Eight primers originally designed for priming casting alloys (Acryl Bond, AC; All Bond II Primer B, BP; Alloy Primer, AP; Estenia Opaque Primer, EP; Eye Sight Opaque Primer, EY; M.L. Primer, ML; MR. Bond, MR; and Super-Bond Liquid, SB) were assessed as bonding promoters. All the primers were a single liquid and contained at least one functional monomer. A selfpolymerizing resin consisting of initiator, monomer liquid, and powder (Super-Bond, Sun Medical Co., Ltd., Moriyama, Japan) was selected as the luting agent. The initiator was partially oxidized tri-n-butylborane (TBB). The monomer liquid was methyl methacrylate (MMA) with 5\% 4-methacryloyloxyethyl trimellitate anhydride (4META). The powder was a finely pulverized poly(methyl methacrylate) (PMMA) with titanium dioxide pigment (Super-Bond Opaque Ivory powder). Information on the materials is summarized in Table 1.

A total of 144 pairs of specimens were wet-ground with a series of silicon-carbide ( $\mathrm{SiC}$ ) abrasive papers (400, 800 , and 1,500 grit) and ultrasonically cleaned with acetone. The 144 disk pairs were divided into nine sets (eight primers and unprimed control, UP) of 16 specimen pairs. A piece of plastic tape with a circular hole $5 \mathrm{~mm}$ in diameter and $50 \mu \mathrm{m}$ in thickness was positioned on the surface of the wide-diameter disk to define the area of the bond. Except for the control specimens (16 pairs), 128 disk pairs were primed with one of the eight primers, and airdried. The 8- and 10-mm disks were bonded with the Super-Bond resin applied with the brush-dip technique. After bonding, a 5.0-N load was applied to the specimens for 30 minutes until setting of the resin material.

The bonded specimens were next immersed in water at $37^{\circ} \mathrm{C}$ for $24 \mathrm{~h}$. This state was defined as 0 thermocycle, and one half of the specimens (nine sets of eight pairs) were shear-tested at this stage. The remaining half of the specimens (nine sets of eight pairs) were subsequently thermocycled in water between $5^{\circ} \mathrm{C}$ and $55^{\circ} \mathrm{C}$ for 100,000 cycles with a 60-s dwell time per bath (Thermal Shock Tester TTS-1 LM, Thomas Kagaku Co. Ltd., Tokyo, Japan). Each specimen was positioned in a specimen holder and the shear bond strength was determined with a mechanical testing device (Type 5567, Instron Corp., Canton, MA, USA) at a cross-head speed of $0.5 \mathrm{~mm}$ per minute. The average shear bond strength and eight replications were calculated for each group.

The results were primarily analyzed by the Levene test for evaluation of equality of variance (SPSS 15.0, SPSS

Table 1 Materials assessed

\begin{tabular}{|c|c|c|c|c|}
\hline Material & Abbr. & Manufacturer & Lot number & Composition (\%) \\
\hline \multicolumn{5}{|l|}{ Substrate material } \\
\hline Sintered alumina & & Furuuchi Chemical Corp., Tokyo., Japan & & $99.7 \mathrm{Al}_{2} \mathrm{O}_{3}, 0.08 \mathrm{SiO}_{2}, 0.05 \mathrm{MgO}$ \\
\hline \multicolumn{5}{|l|}{ Primer } \\
\hline Alloy Primer & AP & Kuraray Medical Inc., Tokyo, Japan & 0264AA & MDP, VBATDT, Acetone \\
\hline Eye Sight Opaque Primer & EY & $\begin{array}{l}\text { Mutsumi Chemical Ind. Co., Ltd., } \\
\text { Yokkaichi, Japan }\end{array}$ & A5Y & MP, Solvent \\
\hline Estenia Opaque Primer & $\mathrm{EP}$ & Kuraray Medical Inc. & $0150 \mathrm{BA}$ & MDP, Solvent \\
\hline MR. Bond & MR & Tokuyama Dental Corp., Tokyo, Japan & $0060 Y 7$ & MMA, MAC-10 \\
\hline M. L. Primer & ML & Shofu Inc., Kyoto, Japan & 70726 & 10-MDDT, 6-MHPA, Acetone \\
\hline Super-Bond Liquid & SB & Sun Medical Co., Ltd., Moriyama, Japan & RL3 & 4-META, MMA \\
\hline All Bond II Primer B & $\mathrm{BP}$ & Bisco, Inc., Schaumburg, IL, USA & 700007751 & BPDM \\
\hline Acryl Bond & $\mathrm{AC}$ & Shofu Inc. & 110625 & 4-AETA, 2-HEMA, MMA \\
\hline \multicolumn{5}{|l|}{ Luting agent } \\
\hline Super-Bond Catalyst & & Sun Medical Co., Ltd. & RL43 & TBB \\
\hline Super-Bond Liquid & & Sun Medical Co., Ltd. & RL3 & 4-META, MMA \\
\hline Super-Bond Opaque Powder & & Sun Medical Co., Ltd. & RF1 & PolyMMA (PMMA), $\mathrm{TiO}_{2}$ \\
\hline
\end{tabular}

MDP, 10-methacryloyloxydecyl dihydrogen phosphate; VBATDT, 6-(4-vinylbenzyl- $n$-propyl) amino-1,3,5-triazine-2,4-dithione; MP, methacrylate-phosphate; MMA, methyl methacrylate; MAC-10, 11-methacryloyloxy-1,1-undecane dicarboxylic acid; 10-MDDT, 10-methacryloyloxydecyl-6,6-dithiooctanoate; 6-MHPA, 6-methacryloyloxyhexyl phosphonoacetate; 4-META, 4-methacryloyloxyethyl trimellitate anhydride; BPDM, Adduct of 2-HEMA and 3,4,4',5'-biphenyl tetracarboxylic anhydride; 4-AETA, 4-acryloyloxyethyl trimellitate anhydride; 2-HEMA, 2-hydroxyethyl methacrylate; TBB, tri- $n$-butylborane 
Table 2 Shear bond strength median, mean, and standard deviation in MPa

\begin{tabular}{|c|c|c|c|c|c|c|c|c|c|c|c|c|c|c|}
\hline \multirow[b]{2}{*}{ Primer } & \multicolumn{4}{|c|}{0 thermocycle } & \multicolumn{9}{|c|}{100,000 thermocycles } & \multirow[b]{2}{*}{$P$ value } \\
\hline & Median & IQR & Mean(SD) & Categories & Median & IQR & Mean(SD) & & gories & & & & & \\
\hline AP & 44.5 & 2.4 & $44.3(1.5)$ & a & 45.2 & 8.9 & $42.8(4.5)$ & $\mathrm{b}$ & $\mathrm{c}$ & & & & & $P=0.96$ \\
\hline EY & 43.4 & 1.4 & $43.1(1.1)$ & a & 42.3 & 3.5 & $42.0(2.5)$ & $\mathrm{b}$ & & & & & & $P=0.39$ \\
\hline EP & 44.5 & 1.5 & $44.2(1.1)$ & a & 43.0 & 6.5 & $41.8(3.5)$ & $\mathrm{b}$ & c & 1 & & & & $P=0.20$ \\
\hline MR & 43.2 & 1.9 & $42.9(1.0)$ & $\mathrm{a}$ & 37.0 & 7.8 & $37.1(4.4)$ & $\mathrm{b}$ & & & $\mathrm{e}$ & & & $P=0.03 *$ \\
\hline ML & 43.1 & 1.2 & $43.1(0.8)$ & a & 37.9 & 9.0 & $36.5(5.9)$ & $\mathrm{b}$ & & & $\mathrm{f}$ & $\mathrm{g}$ & $\mathrm{h}$ & $P<0.01^{*}$ \\
\hline UP & 43.4 & 2.3 & $43.3(1.3)$ & $\mathrm{a}$ & 35.0 & 4.5 & $35.8(3.0)$ & $\mathrm{b}$ & & & $\mathrm{f}$ & & & $P<0.01^{*}$ \\
\hline SB & 43.1 & 2.4 & $43.3(1.2)$ & a & 35.5 & 6.6 & $34.4(3.6)$ & & $\mathrm{c}$ & 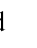 & e $\mathrm{f}$ & $\mathrm{g}$ & & $P<0.01^{*}$ \\
\hline BP & 44.6 & 3.6 & $44.1(2.3)$ & a & 25.3 & 10.6 & $25.7(5.4)$ & & & & e & g & $\mathrm{h}$ & $P<0.01^{*}$ \\
\hline $\mathrm{AC}$ & 43.7 & 2.4 & $43.7(1.2)$ & $\mathrm{a}$ & 21.2 & 5.7 & $22.0(4.5)$ & & & & e & & $\mathrm{h}$ & $P<0.01^{*}$ \\
\hline
\end{tabular}

Inc., Chicago, IL, USA). The results were then analyzed by Kruskal-Wallis test (SPSS ver.15.0), followed by SteelDwass test (Kyplot 4.0, KyensLab Inc., Tokyo, Japan) at a significance level of $P<0.05$. Differences between the pre- and post-thermocycling bond strengths for an identical priming condition were analyzed with the Mann-Whitney $U$ test (SPSS ver.15.0).

After the shear testing, the debonded surfaces were observed through an optical microscope (8x; SZX9, Olympus Corp., Tokyo, Japan). The failure modes were classified into the following three categories: A, adhesive failure at the luting agent-alumina interface; $\mathrm{C}$, cohesive failure within the luting agent; and CA, combination of cohesive and adhesive failures.

\section{Results}

The Levene test run on the pre- and post-thermocycling groups did not show equality of variance for several groups. The Kruskal-Wallis test showed that $\chi^{2}$ values were 10.520 for the pre-thermocycling group and 48.754 for the postthermocycling group. The $P$ value was 0.230 for prethermocycling bond strengths, whereas the $P$ value was less than 0.05 for post-thermocyclintg bond strength. The post-thermocycling results were therefore analyzed by Steel-Dwass multiple comparisons. In addition, the differences between pre- and post-thermocycling bond strengths for an identical priming condition were analyzed by Mann-Whitney $U$ test.

Results of shear bond testing are summarized in Table 2. Pre-thermocycling average bond strengths varied from a minimum of $42.9 \mathrm{MPa}$ to a maximum of $44.3 \mathrm{MPa}$, and they were not significantly different from each other (category a). Post-thermocycling average bond strengths
Table 3 Failure mode after the shear bond testing

\begin{tabular}{|c|c|c|c|c|c|c|}
\hline \multirow{2}{*}{$\begin{array}{l}\text { Primer } \\
\text { Failure mode }\end{array}$} & \multicolumn{3}{|c|}{0 thermocycle } & \multicolumn{3}{|c|}{100,000 thermocycles } \\
\hline & A & $\mathrm{AC}$ & $\mathrm{C}$ & A & $\mathrm{AC}$ & $\mathrm{C}$ \\
\hline AP & 6 & 4 & 0 & 6 & 2 & 0 \\
\hline EY & 8 & 0 & 0 & 8 & 0 & 0 \\
\hline EP & 6 & 2 & 0 & 8 & 0 & 0 \\
\hline MR & 8 & 0 & 0 & 8 & 0 & 0 \\
\hline ML & 7 & 1 & 0 & 8 & 0 & 0 \\
\hline UP & 8 & 0 & 0 & 8 & 0 & 0 \\
\hline SB & 8 & 0 & 0 & 8 & 0 & 0 \\
\hline BP & 8 & 0 & 0 & 8 & 0 & 0 \\
\hline $\mathrm{AC}$ & 8 & 0 & 0 & 8 & 0 & 0 \\
\hline
\end{tabular}

UP, Unprimed control.

A, Adhesive failure at the aluminum oxide interface; $\mathrm{C}$, Cohesive failure within the luting agent;

$\mathrm{AC}$, Combination of adhesive and cohesive failures.

varied from 22.0 MPa to 42.8 MPa, and were categorized into seven groups (categories b-h). Among the postthermocycling groups, six groups recorded the greatest bond strength (category b). Comparison between the pre- and post-thermocycling results revealed that the bond strength of three groups (AP, EY, and EP) was not significantly reduced by application of thermocycling $(P>0.05)$, whereas the bond strength of six groups (MR, ML, UP, $\mathrm{SB}, \mathrm{BP}$, and $\mathrm{AC}$ ) was significantly reduced after thermocycling $(P<0.05)$.

Results of failure mode analysis are summarized in Table 3. None of the specimens showed cohesive failure within the experimental conditions employed. A combination of adhesive and cohesive failures was detected for 


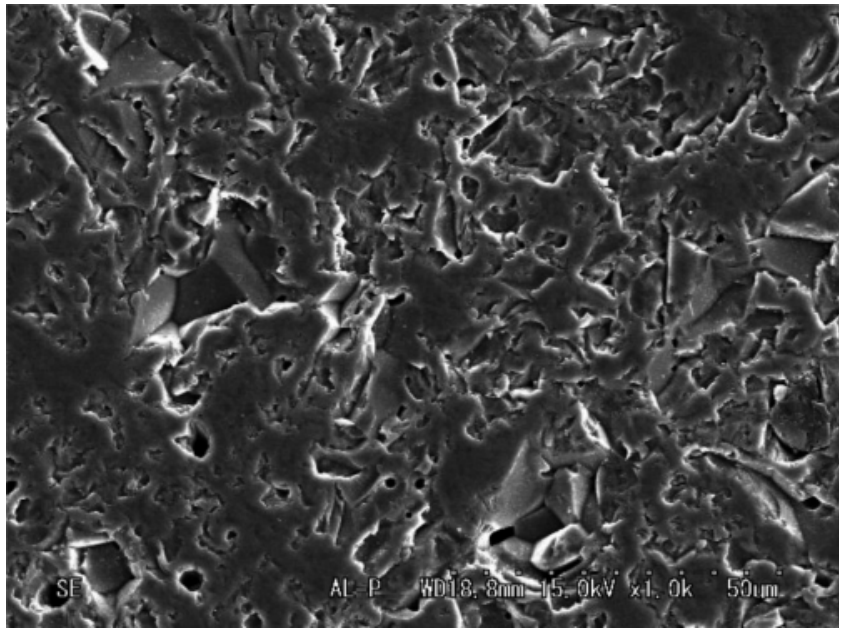

Fig. 1 Scanning electron micrograph of ground alumina.

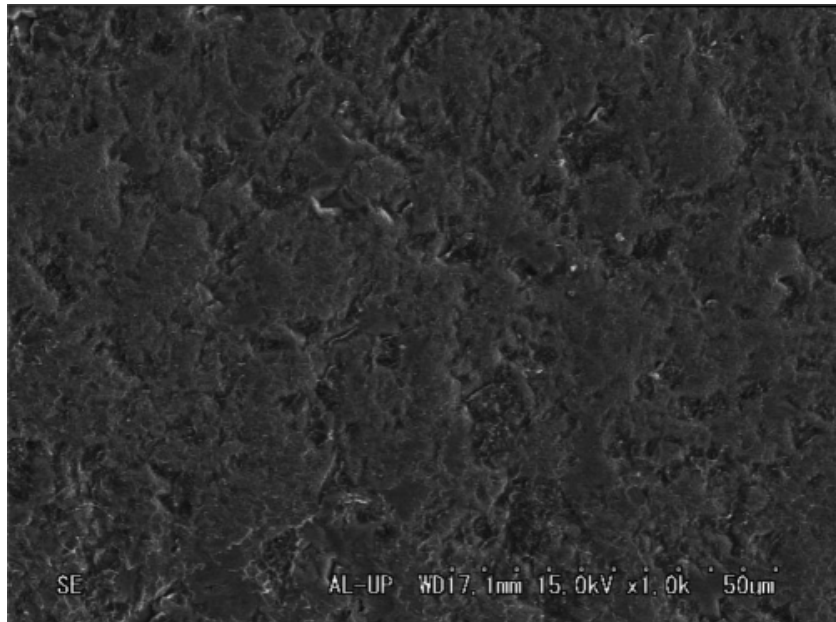

Fig. 2 Debonded surface of an unprimed thermocycled specimen.

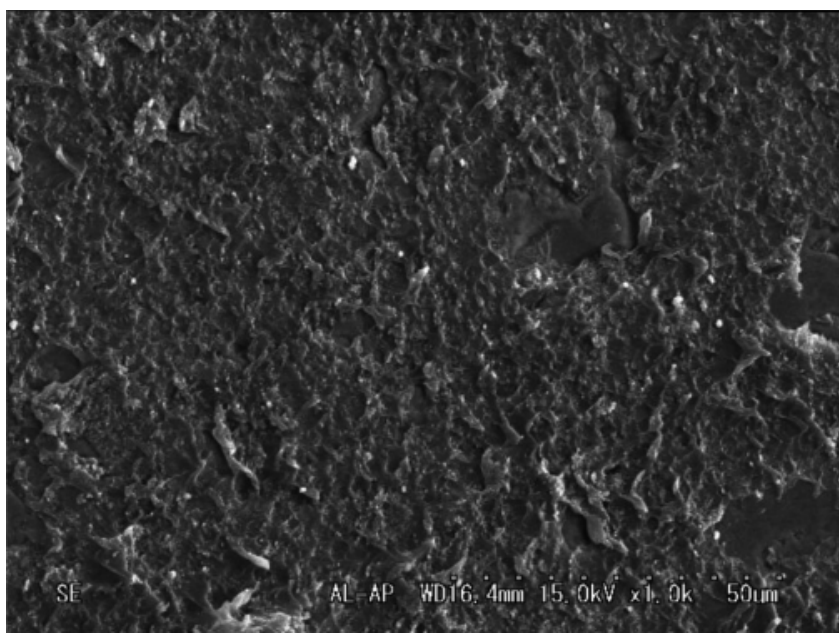

Fig. 3 Debonded surface of a thermocycled specimen primed with Alloy Primer. the AP, EP, and ML groups before thermocycling, and for the AP group after thermocycling. The remaining specimens were judged to show adhesive failure.

Figure 1 shows a scanning electron micrograph of the ground alumina surface before bonding. A complex relief pattern probably generated by sintering alumina can be seen. Figures 2-5 show the debonded surfaces of thermocycled alumina originally bonded with four adhesive systems. Figure 2 shows the appearance of adhesive failure at the alumina surface attributable to lack of resin remaining at the alumina surface. However, the micrograph indicates that fractured resin is still present inside the small voids. Figures 3 and 4 show debonded specimens in the AP and EY groups. Remnants of resin material can be detected. Figure 5 is the debonded surface of a specimen in the AC

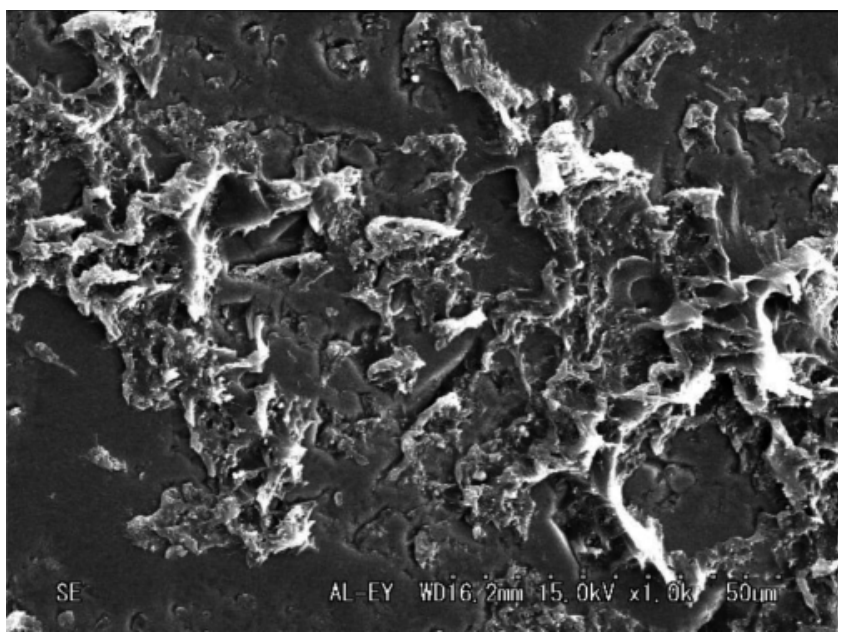

Fig. 4 Debonded surface of a thermocycled specimen primed with Eye Sight Opaque Primer.

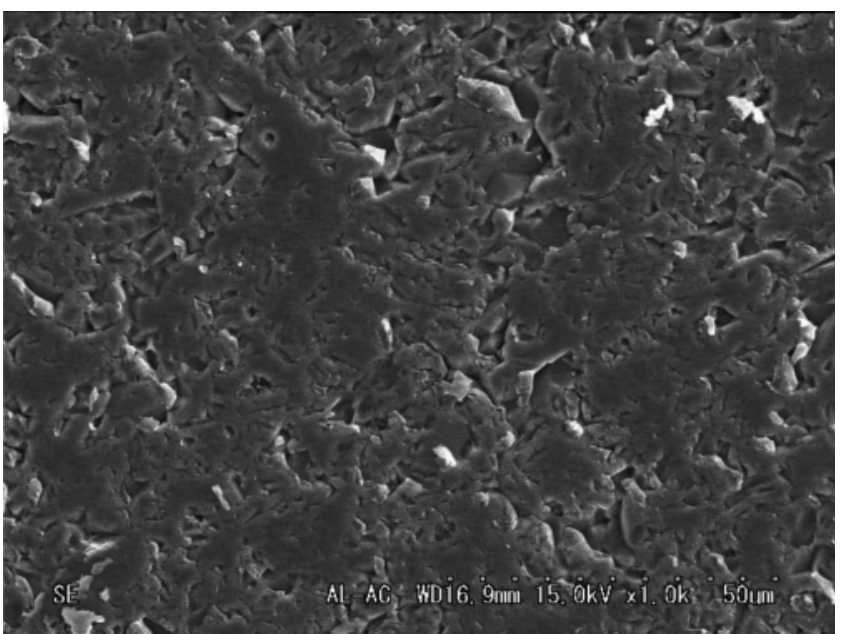

Fig. 5 Debonded surface of a thermocycled specimen primed with Acryl Bond. 
group. The surface has an appearance similar to that of the ground alumina specimen.

\section{Discussion}

This study evaluated the bonding characteristics of sintered alumina using acidic primers and a TBB-initiated Super-Bond resin. An alumina substrate was used without mechanical surface preparation because the purpose of the study was to evaluate the effect of acidic functional monomers on chemical bonding rather than the effect of mechanical retention. However, sintered alumina exhibited a fused crystalline structure with multiple voids (Fig. 1). As a result, the surface may be mechanically retentive.

This study used Super-Bond resin as the luting agent. This resin did not contain a tertiary amine reducing agent. This composition made it possible to evaluate the effect of acidic functional monomers in the primers or luting agents. Super-Bond resin contains carboxylic 4-META monomer in the liquid component. Due to its carboxylic structure, 4-META may positively influence the strength of bonding of TBB-initiated resin to alumina. The authors therefore primarily evaluated the effect of acidic monomers on the bond strength to alumina of TBB-initiated resin without 4-META (15). The results showed that effect of 4-META was ranked as moderate among the eight primers. The authors used eight acidic primers and Super-Bond resin considering the possibility of combined application of acidic primers and the Super-Bond resin.

The results (Table 2) demonstrated that the phosphate primers (AP, EY, and EP) had better bond performance than the others, although the statistical categories overlapped. This was probably due to the difference in bonding ability between the phosphate monomer and other acidic monomers. Other studies have demonstrated the effectiveness of MDP monomer for bonding dental base metal alloys (20-22) and zirconia (23-24). Base metal alloys and zirconia are usually covered with a metal oxide layer. Considering the fact that MDP is effective for bonding base metals or metal oxides, it is not contradictory to the experimental result that MDP monomer is useful for bonding alumina, because alumina is also an oxide of aluminum metal.

Sen et al. (18) reported that the Panavia luting agent, based on MDP, showed higher bond strength than the 4META-based Super-Bond resin for bonding In-Ceram glass-infiltrated alumina. At least three factors can be considered when evaluating the difference between Panavia and Super-Bond materials: the matrix system, the initiator, and the functional monomer. The present experiment unified the luting resin and the initiator, and the remaining factor, the functional monomer, was evaluated using eight primers. It was found that phosphate primers demonstrated reliable bonding performance without a reduction in bond strength after thermocycling. This supports the hypothesis that phosphate-based monomer is a suitable compound for priming alumina, within the limitations of the present experimental conditions.

It is important for clinicians to employ a compatible bonding system, taking into consideration the relationship between the functional monomer and the substrate composition. It can be concluded that the use of acidic primers containing hydrophobic phosphate is recommended for bonding sintered alumina with the TBB-initiated SuperBond resin.

\section{Acknowledgments}

This work was supported in part by a Grant-in-Aid for Scientific Research (C 20592302) from the Japan Society for the Promotion of Science (JSPS), a Special Research Grant for the Development of Distinctive Education from the Promotion and Mutual Aid Corporation for Private Schools of Japan (2009 and 2010), a Grant from the Dental Research Center, Nihon University School of Dentistry (B 2009, 2010), and the Sato Fund, Nihon University School of Dentistry (2010).

\section{References}

1. McLean JW, Hughes TH (1965) The reinforcement of dental porcelain with ceramic oxides. Br Dent J 119, 251-267.

2. Andersson M, Odén A (1993) A new all-ceramic crown. A dense-sintered, high-purity alumina coping with porcelain. Acta Odontol Scand 51, 59-64.

3. Matsumura H, Nakamura M, Nakabayashi N, Tanaka T, Atsuta M (1987) Effect of a silane coupling agent and ferric chloride on the bonding of porcelain, quartz and alumina with 4-META/MMA-TBB resin. Dent Mater J 6, 135-139.

4. Awliya W, Odén A, Yaman P, Dennison JB, Razzoog ME (1998) Shear bond strength of a resin cement to densely sintered high-purity alumina with various surface conditions. Acta Odontol Scand 56, 9-13.

5. Blixt M, Adamczak E, Lindén LA, Odén A, Arvidson K (2000) Bonding to densely sintered alumina surfaces: effect of sandblasting and silica coating on shear bond strength of luting cements. Int J Prosthodont 13, 221-226.

6. Friederich R, Kern M (2002) Resin bond strength to densely sintered alumina ceramic. Int $\mathrm{J}$ Prosthodont 15, 333-338.

7. Blatz MB, Sadan A, Arch GH Jr, Lang BR (2003) In vitro evaluation of long-term bonding of Procera 
AllCeram alumina restorations with a modified resin luting agent. J Prosthet Dent 89, 381-387.

8. Blatz MB, Sadan A, Blatz U (2003) The effect of silica coating on the resin bond to the intaglio surface of Procera AllCeram restorations. Quintessence Int 34, 542-547.

9. Blatz MB, Sadan A, Soignet D, Blatz U, Mercante D, Chiche G (2003) Long-term resin bond to densely sintered aluminum oxide ceramic. J Esthet Restor Dent 15, 362-368.

10. Sadan A, Blatz MB, Soignet D (2003) Influence of silanization on early bond strength to sandblasted densely sintered alumina. Quintessence Int 34, 172176.

11. Hummel M, Kern M (2004) Durability of the resin bond strength to the alumina ceramic Procera. Dent Mater 20, 498-508.

12. Piwowarczyk A, Lauer HC, Sorensen JA (2004) In vitro shear bond strength of cementing agents to fixed prosthodontic restorative materials. J Prosthet Dent 92, 265-273.

13. Valandro LF, Della Bona A, Antonio Bottino M, Neisser MP (2005) The effect of ceramic surface treatment on bonding to densely sintered alumina ceramic. J Prosthet Dent 93, 253-259.

14. Valandro LF, Ozcan M, Bottino MC, Bottino MA, Scotti R, Bona AD (2006) Bond strength of a resin cement to high-alumina and zirconia-reinforced ceramics: the effect of surface conditioning. J Adhes Dent 8, 175-181.

15. Yamada K, Koizumi H, Kawamoto Y, Ishikawa Y, Matsumura H, Tanoue N (2007) Effect of singleliquid priming agents on adhesive bonding to aluminum oxide of a methacrylic resin. Dent Mater J 26, 642-646.

16. Yamada K, Koizumi H, Ishikawa Y, Matsumura $H$ (2008) Effect of single-liquid acidic primers on bonding of a composite luting agent joined to a prefabricated alumina coping material. Nihon Hotetsu Shika Gakkai Zasshi 52, 189-193.

17. Kern M, Thompson VP (1995) Bonding to glass infiltrated alumina ceramic: adhesive methods and their durability. J Prosthet Dent 73, 240-249.

18. Sen D, Poyrazoglu E, Tuncelli B, Göller G (2000) Shear bond strength of resin luting cement to glassinfiltrated porous aluminum oxide cores. J Prosthet Dent 83, 210-215.

19. Komine F, Tomic M, Gerds T, Strub JR (2004) Influence of different adhesive resin cements on the fracture strength of aluminum oxide ceramic posterior crowns. J Prosthet Dent 92, 359-364.

20. Matsumura H, Tanaka T, Taira Y, Atsuta M (1996) Bonding of a cobalt-chromium alloy with acidic primers and tri-n-butylborane-initiated luting agents. J Prosthet Dent 76, 194-199.

21. Yanagida H, Matsumura H, Atsuta M (2001) Bonding of prosthetic composite material to Ti$6 \mathrm{Al}-7 \mathrm{Nb}$ alloy with eight metal conditioners and a surface modification technique. Am J Dent 14, 291 294.

22. Suzuki M, Yamamoto M, Fujishima A, Miyazaki T, Hisamitsu H, Kojima K, Kadoma Y (2002) Raman and IR studies on adsorption behavior of adhesive monomers in a metal primer for $\mathrm{Au}, \mathrm{Ag}, \mathrm{Cu}$, and Cr surfaces. J Biomed Mater Res 62, 37-45.

23. Kern M, Wegner SM (1998) Bonding to zirconia ceramic: adhesion methods and their durability. Dent Mater 14, 64-71.

24. Nakayama D, Koizumi H, Komine F, Blatz MB, Tanoue N, Matsumura H (2010) Adhesive bonding of zirconia with single-liquid acidic primers and a tri-n-butylborane initiated acrylic resin. J Adhes Dent 12, 305-310. 